\title{
COMPACT QUASI SELF-COMPLEMENTARY ELLIPTICAL DISC MONOPOLE ANTENNA WITH TAPERED MICROSTRIP FEED LINE
}

\author{
Jasmine Mannil Abraham ${ }^{1}$, G. Josemin Bala ${ }^{2}$ \\ ${ }^{1}$ PG Scholar, Department of Electronics and Communication Engineering, Karunya University, Tamil Nadu, India \\ ${ }^{2}$ Professor, Department of Electronics and Communication Engineering, Karunya University, Tamil Nadu, India
}

\begin{abstract}
In this paper a compact elliptical disc monopole antenna with tapered microstrip feed line for UWB application is proposed. The antenna is designed using the quasi self -complementary technique for attaining electrical as well as physical size reduction. A triangular notch is included in the ground plane for impedance matching between the antenna and the RF front end. The adoption of this miniaturization technique has narrowed the impedance bandwidth of the antenna in the UWB range but lead to an additional operating bandwidth in Ku band thereby exhibiting dual band behavior. This reduction in the bandwidth in the UWB range was overcome by using the tapered microstrip feed line configuration. The antenna exhibited a wide impedance bandwidth extending beyond the UWB range and hence could be used for both UWB as well as Ku band applications. The antenna has a physical dimension of $16 \mathrm{~mm} X 25 \mathrm{~mm}$ corresponding to an electrical size of $0.24 \lambda$ and was designed on an FR4 substrate with $\varepsilon r$ of 4.7. It is seen that the antenna proposed here has led to $62 \%$ size reduction with a percentage impedance bandwidth of $123.46 \%$ when compared with the conventional elliptical disc monopole antenna.
\end{abstract}

Keywords: Quasi self-complementary technique, planar monopole antennas, miniaturization, tapered microstrip feed line, bandwidth enhancement, UWB antennas

\section{INTRODUCTION}

The FCC (Federal Communications Committee) allocated a bandwidth of $7.5 \mathrm{GHz}$ extending from $3.1 \mathrm{GHz}$ to $10.6 \mathrm{GHz}$ for UWB (Ultra Wideband) applications. Since then UWB technologies have evolved tremendously. The UWB is a communication technology that occupies more than $500 \mathrm{MHz}$ bandwidth or greater than $25 \%$ operating frequency. UWB technology has several advantages which has made it highly attractive for consumer communication applications. It has proved to be one of the most promising technologies for high data rate wireless transmissions and has helped in improving the services and facilities provided to the end users.

The advantages possessed by UWB antennas has led to an increasing demand for improved performances, higher data rate transmissions and synonymous operation with several other techniques. Thus it was required to extend the antenna performance beyond $10.6 \mathrm{GHz}$ which is presently the upper limit allotted by FCC for UWB systems. Apart from this there has also been a greater demand for small and compact UWB antennas as they could be easily incorporated in all mobile electronics. A UWB antenna should not only be capable of working over the entire UWB band assigned by the FCC but also should be compact for the easy integration requirement of the UWB systems. To sum it up, miniaturization and bandwidth enhancement are two major concerns, in the context of UWB antennas for which several techniques have been adopted over the recent years.

Various miniaturization techniques have been adopted over the past few decades to develop compact UWB antennas whilst maintaining antenna performance [11-13]. Top loading the back side of a microstrip fed elliptical monopole antenna [13] has led to miniaturized physical size of $25 \mathrm{~mm}$ X $26 \mathrm{~mm}$. The elliptical radiator was modified to obtain a better performance in the higher frequency range. Reduced ground plane effect was also employed to obtain a compact antenna [7]. This effect was introduced by cutting a rectangular notch from the patch and attaching an asymmetrical strip to the radiator. The resulting antenna had a physical size of $25 \mathrm{~mm} \mathrm{X}$ $25 \mathrm{~mm}$ and displayed considerable performance in the UWB range. Antenna miniaturization can also be attained by increasing the dielectric constant of the substrate [13]. The surface wave excitations that may be caused by the use of a substrate with higher dielectric constant can be removed by reducing the thickness of the substrate. An antenna designed using this technique can have a dimension of $20 \mathrm{~mm} \mathrm{X} 26 \mathrm{~mm}$ physically. Techniques adopted for impedance bandwidth enhancement for monopole antennas include ground plane modification, tapered microstrip feed line and dual microstrip feed line. Ground plane modification is the widely used method which has proved to provide an impedance bandwidth from $3.1 \mathrm{GHz}$ to $12.6 \mathrm{GHz}$ when used for an elliptical disc monopole antenna [2]. The ground plane was modified from 
rectangular to half circular with sleeves included in the ground plane for further enhancement of the impedance bandwidth. The dual microstrip feed line when used in conjunction with a circular patch gives considerable return loss performance up to $15 \mathrm{GHz}$ when compared to a circular disc monopole antenna fed with the conventional microstrip feed line [3].

Apart from all the miniaturization techniques available the quasi self-complementary structure can be employed for reducing the physical size of the antenna. The striking and the most remarkable feature of this technique is that it can lead to electrical size reduction along with the reduction in the physical size. However it is seen that the antenna employing this structure has a constant impedance of $188.5 \Omega$ irrespective of the antenna geometry thus requiring an external impedance matching circuit to transform the $188.5 \Omega$ impedance of the antenna to the $50 \Omega$ impedance of the RF front end. This requirement limits the miniaturization that could be attained by the antenna. To combat this, modifications in the antenna geometry was taken up for impedance matching. But this led to a reduction in the impedance bandwidth of the antenna. In order to overcome this bandwidth limitation, a tapered microstrip feed line is used in conjunction with the quasi self-complementary structure. Thus, in effect a compact UWB antenna design that could operate over an enhanced bandwidth was obtained.

This paper presents a compact quasi self-complementary elliptical disc monopole antenna fed by a tapered microstrip feed line. Theoretically, an antenna designed using the QSC technique has an impedance of $188.5 \Omega$. Hence a matching circuit is needed to transform the impedance of the antenna from $188.5 \Omega$ to $50 \Omega$ in order to match the impedance of the antenna with that of the RF front end. For this triangular notch is included in the ground plane, thereby avoiding the use of any external circuits for impedance matching and adding to antenna miniaturization. The inclusion of notch for impedance matching has reduced the impedance bandwidth of the antenna over the UWB range. This defect was overcome by using a tapered microstrip feed line and has led to an impedance bandwidth extending up to the Ku band. An elliptical patch and microstrip feed line was chosen to a circular patch and CPW feed line respectively because it helps in achieving better size reduction than the latter case. The performance of this antenna is compared with a compact QSC antenna employing a conventional microstrip feed line.

\section{SELF-COMPLEMENTARY ANTENNA}

The self-complementary antenna was first proposed by Mushiake [14 and16]. He claimed that an antenna designed using this technique can attain a broad impedance bandwidth. Theoretically self-complementary antennas possess a constant impedance of $188.5 \Omega$ independent of the source frequency and the antenna configuration. From [17] it is seen that a selfcomplementary antenna can be represented by a pair of complementary slot and dipole antenna as shown in Fig.1. The terminals of the antenna, denoted by FF are separated by a small infinitesimal distance as shown in Fig.1 (a) and Fig.1 (b). It is also assumed that the slot and the dipole are cut from an infinitesimal thin plane, perfectly conducting sheet. The ratio of the terminal voltage Vs to the terminal current Is gives the driving point impedance $\mathrm{Zs}$ at the terminals of the slot antenna shown in Fig. 1(a) while $\mathrm{Zd}$ is the ratio of the terminal voltage $\mathrm{Vd}$ to the terminal current Id of the dipole antenna in Fig. 1 (b). After derivations in [16], it is found that the product of the impedances of two complementary antennas is the constant $\mathrm{Zo}^{2} / 4$, where $\mathrm{Zo}$ is the intrinsic impedance of the surrounding medium.

Frequency-independent impedance behavior can be achieved if the antenna is its own complement. This is the selfcomplementary property, in which the antenna and its complement are identical. Through translation or rotation a self-complementary structure can be made to exactly overlay its complement. The value of impedance follows directly from the equation, as noted by Mushiake:

$$
Z=Z s=Z d=Z o / 2=188.5 \Omega
$$
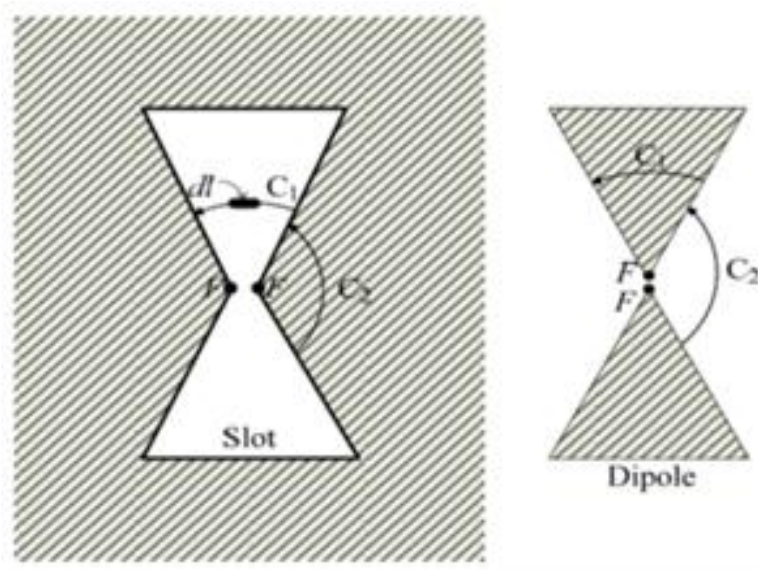

Fig -1: Slot antenna and its complementary dipole antenna

Therefore, in theory, a perfect self-complementary antenna on an infinitely large plane has the constant input impedance $188.5 \Omega$, independent of the source frequency and the shape of the antenna. Practically a self-complementary antenna has to be truncated on a finite plane, which limits its bandwidth. Furthermore, an impedance matching circuit for transforming $188.5 \Omega$ to $50 \Omega$ will further narrow the bandwidth and limit the reduction of antenna size. In this paper a triangular notch is included in the ground plane for matching the $188.5 \Omega$ impedance of the quasi self-complementary antenna to the 50 $\Omega$ impedance of the RF front end, thereby avoiding the use of any external matching circuits and thus adding to the advantage of higher miniaturization. 


\section{ANTENNA DESIGN AND GEOMETRY}

The design procedure for the compact quasi selfcomplementary elliptical disc monopole antenna is shown in Fig.2. At the initial stage a half elliptical patch is formed on one side of the FR4 substrate with its slot counterpart on the other side of the substrate which is made known in Fig. 2(a). Next a tapered microstrip feed line is then added to the radiator to excite it as shown in Fig. 2(b). Fig. 2(c) depicts the final stage where a triangular notch is included in the ground plane for impedance matching.

The compact quasi self-complementary elliptical disc monopole antenna with tapered microstrip feed line proposed in this paper is displayed in Fig.3. The antenna consists of a semi-elliptical patch on one side of the FR4 substrate with permittivity er 4.7 and thickness $1.6 \mathrm{~mm}$. L and $\mathrm{W}$ denote the length and the width of the dielectric substrate, respectively. A and $\mathrm{B}$ represent the semi major and semi minor axes respectively of the semi-elliptical patch. The dimensions of the proposed antenna are displayed in Table 1. Additionally, in order to enhance the impedance matching of the antenna, a triangular notch is proposed on the ground plane. Ws and L2 represent the width and height of the triangular notch respectively. A tapered microstrip feed line is included to enhance the impedance bandwidth of the antenna which otherwise was reduced due to the employment of the QSC structure. CADFEKO simulation software was used for simulating the antenna.
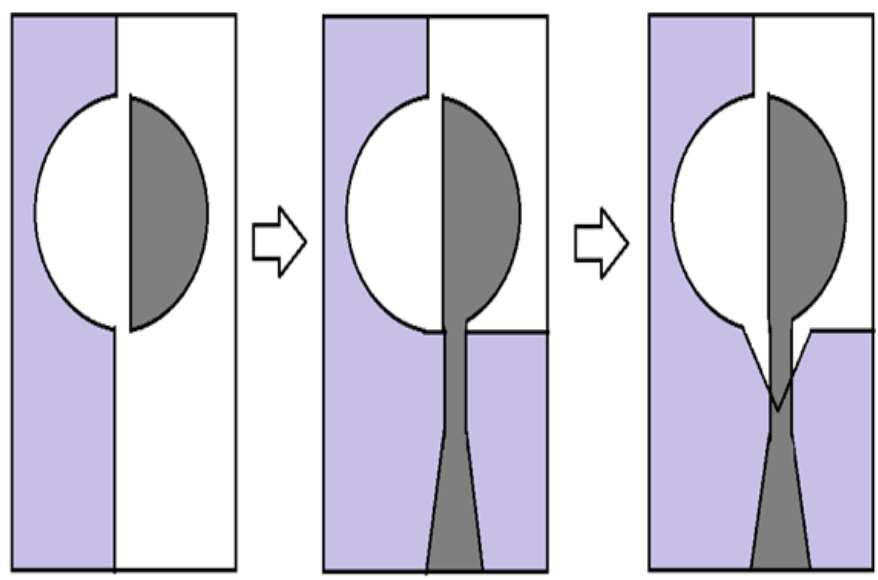

Fig -2: Design process of the compact quasi selfcomplementary elliptical disc monopole antenna with tapered microstrip feed line

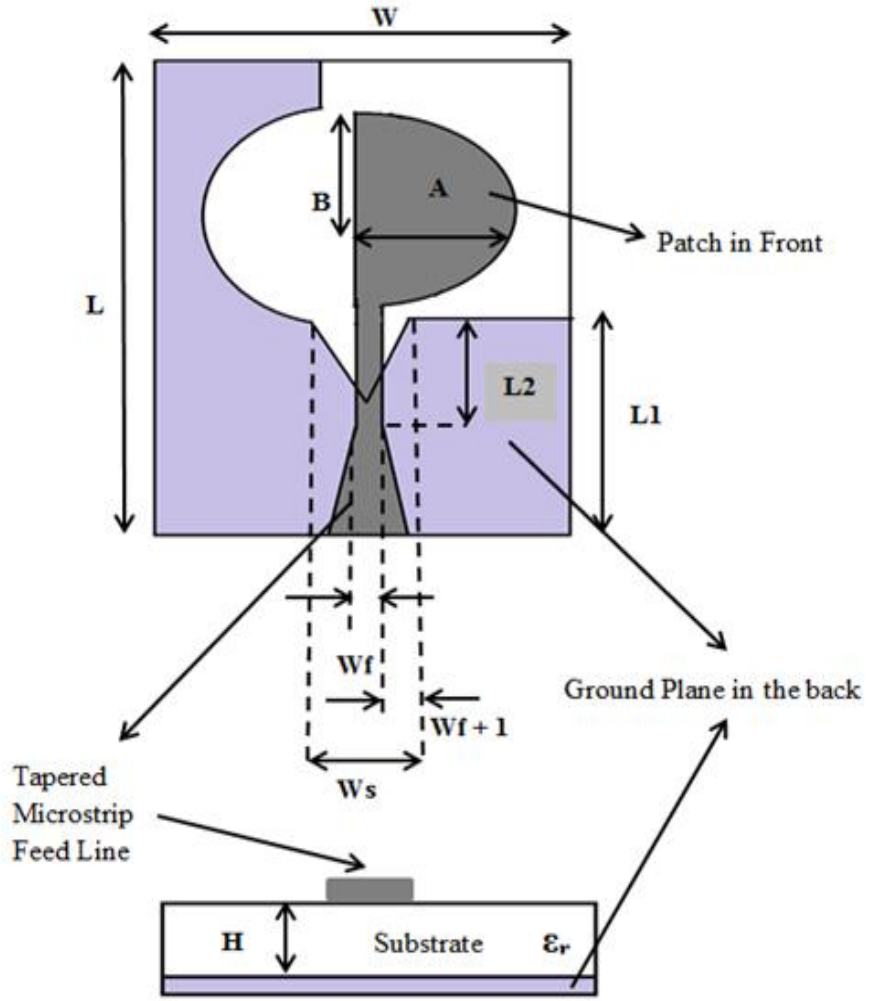

Fig -3: Geometry of the proposed antenna

Table -1: Dimensions of the Proposed Antenna

\begin{tabular}{|c|c|}
\hline Parameter & Dimension $(\mathrm{mm})$ \\
\hline W & 16 \\
\hline L & 25 \\
\hline H & 1.6 \\
\hline A & 6 \\
\hline B & 3.7 \\
\hline Ws & 6 \\
\hline Wf & 2.4 \\
\hline L1 & 8.9 \\
\hline L2 & 4.8 \\
\hline
\end{tabular}

\section{RESULTS AND DISCUSSIONS}

The performance of the antenna is compared with that of the QSC antenna employing a non-tapered microstrip feed line [1]. Fig.4 and Fig.5 depict the front and back view of the QSC elliptical disc monopole antenna without and with the tapered feed line respectively. The triangular notch in the ground plane included for ground plane for impedance matching can be seen in Fig.4 (b) and Fig.5 (b). Fig.5 (a) depicts the tapered microstrip feed line included for impedance bandwidth enhancement. 


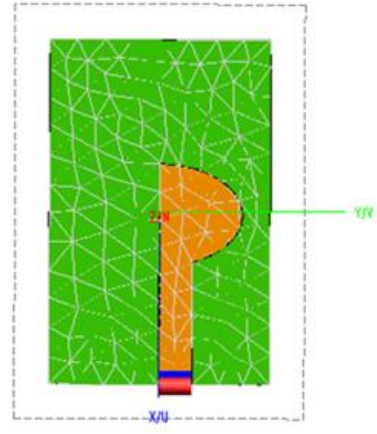

(a)

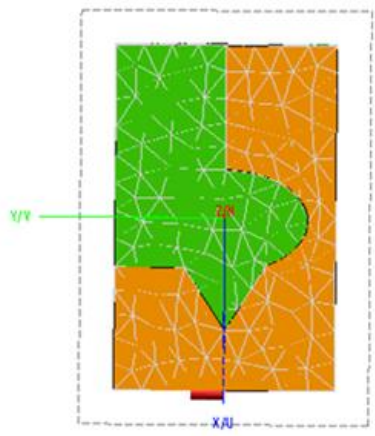

(b)
Fig -4: Front and back view of the compact QSC elliptical disc monopole antenna

Both the antennas were designed using the quasi selfcomplementary concept. The resulting antenna has a physical dimension of $16 \mathrm{~mm}$ X $25 \mathrm{~mm}$ corresponding to an electrical equivalent of $0.24 \lambda$. The inclusion of the tapered microstrip feed line combats the narrowing of the impedance bandwidth caused due to the adoption of this technique for miniaturization

Fig. 6 shows the 3-Dimensional radiation pattern of the compact quasi self-complementary elliptical disc monopole antenna with tapered microstrip feed line. From the figure it can be seen that the antenna exhibits an omni directional radiation pattern which is a required feature for a UWB antenna.

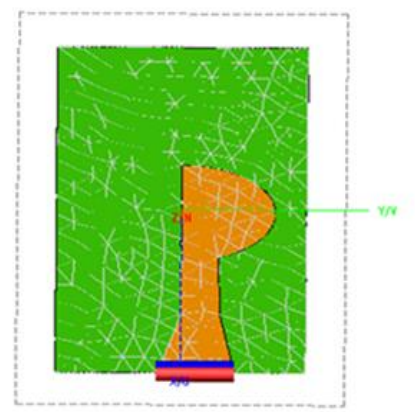

(a)

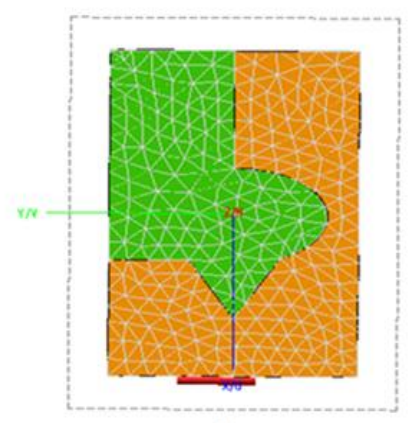

(b)
Fig -5: Front and back view of the QSC elliptical disc monopole antenna with tapered microstrip feed line

The impedance bandwidth of the antenna can be estimated from the return loss graphs. From Fig.7, it is seen that the compact QSC elliptical disc monopole antenna exhibits a narrow impedance bandwidth on the UWB range. The percentage impedance bandwidth of this antenna at fc1 as $7.83 \mathrm{GHz}$ is just $2.17 \%$. This is because of the use of the notch included in the ground plane for impedance matching. But, it is seen that the antenna exhibits another band from $12.32 \mathrm{GHz}$ to $15.53 \mathrm{GHz}$ with center frequency fc2 as $14.6 \mathrm{GHz}$, hence exhibiting dual band operation.

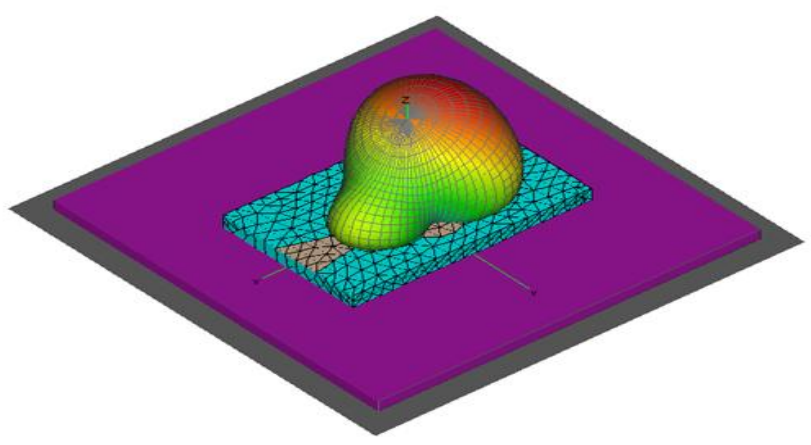

Fig -6: 3-Dimensional Radiation Pattern of the Proposed Antenna

Fig. 8 displays the return loss of the antenna proposed here. It is seen that the antenna is capable of operating over the entire UWB range and beyond thereby eliminating the issue in the earlier case. The inclusion of the tapered microstrip feed line has made the antenna capable of working over the UWB range as well as the $\mathrm{Ku}$ band thereby making the antenna capable of operating over a wider impedance bandwidth extending beyond the UWB range. The percentage impedance bandwidth of the proposed antenna with fc as $9.29 \mathrm{GHz}$ was calculated as $123.46 \%$.

The Voltage Standing Wave Ratio is the parameter that indicates how well the antenna matches to the transmission line. A VSWR of unity is the best that indicates zero reflections and return losses. But this is difficult to achieve for UWB systems. Hence for UWB systems a VSWR $<2$ is considered to be the best. The proposed antenna exhibits a VSWR of $1.3 \mathrm{~dB}$ at $\mathrm{fc}$.

Theoretically the impedance of an antenna must be equivalent to $50 \Omega$. Since quasi self-complementary technique was adopted for miniaturizing the antenna, the antenna's impedance rose to $188.5 \Omega$. This was practically brought down to approximately $49.13 \Omega$ by using a triangular notch in the ground plane thereby matching the impedance of the antenna with that of the RF front end which is depicted in Fig.9 


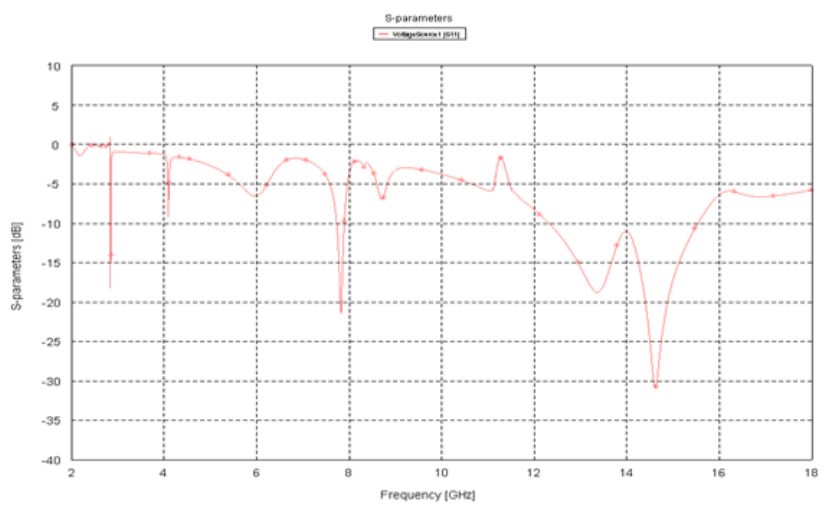

Fig -7: Return Loss of the QSC elliptical disc monopole antenna without the tapered microstrip feed line.

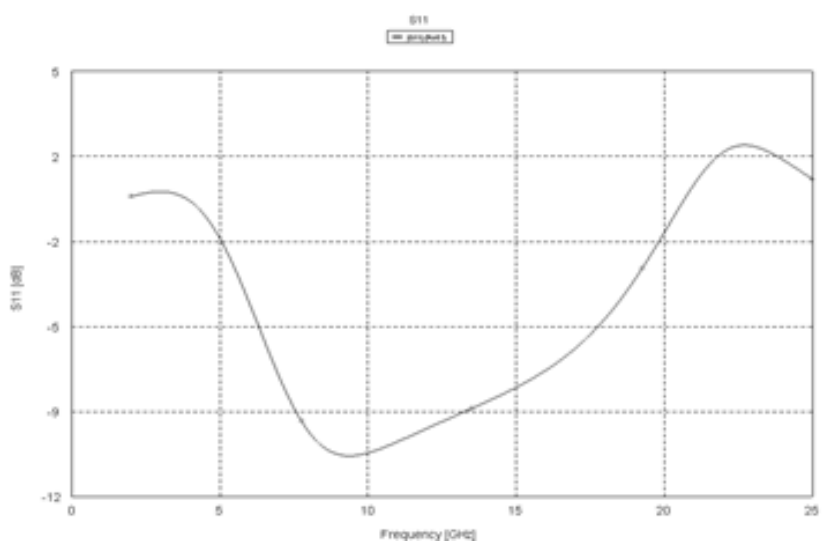

Fig -8: Return Loss of the QSC elliptical disc monopole antenna with tapered microstrip feed line

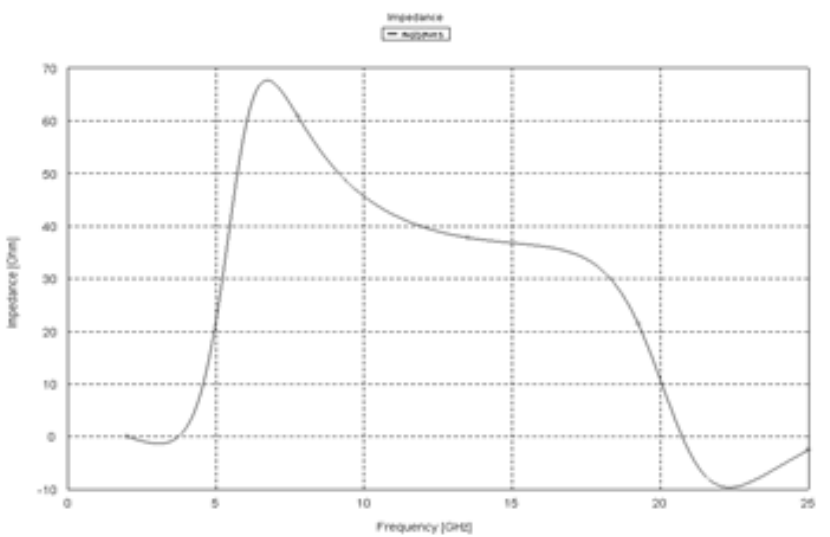

Fig -9: Impedance of the QSC elliptical disc monopole antenna with tapered microstrip feed line

Miniaturization and impedance bandwidth enhancement being the key parameters of concern here, a comparison between the antenna proposed here and the conventional elliptical disc monopole antenna is discussed at this point. It is seen that with the adoption of the quasi self-complementary technique $62 \%$ size reduction was attained when compared with the conventional case. This technique has helped in size diminishment both in the physical domain as well as in the electrical domain as detailed in Table 2

Table -2: Comparison of the Size between the Conventional Elliptical Disc Monopole Antenna with the Antenna Proposed here

\begin{tabular}{|c|c|c|}
\hline Antenna & $\begin{array}{c}\text { Physical Size } \\
(\mathrm{mm})\end{array}$ & $\begin{array}{c}\text { Electrical } \\
\text { Size (mm) }\end{array}$ \\
\hline $\begin{array}{c}\text { Conventional Elliptical Disc } \\
\text { Monopole Antenna }\end{array}$ & $30 \times 35$ & $0.36 \lambda$ \\
\hline $\begin{array}{c}\text { Compact Quasi Self- } \\
\text { Complementary Elliptical } \\
\text { Disc Monopole Antenna } \\
\text { with Tapered Microstrip } \\
\text { Feed Line }\end{array}$ & 16 X 25 & $0.24 \lambda$ \\
\hline
\end{tabular}

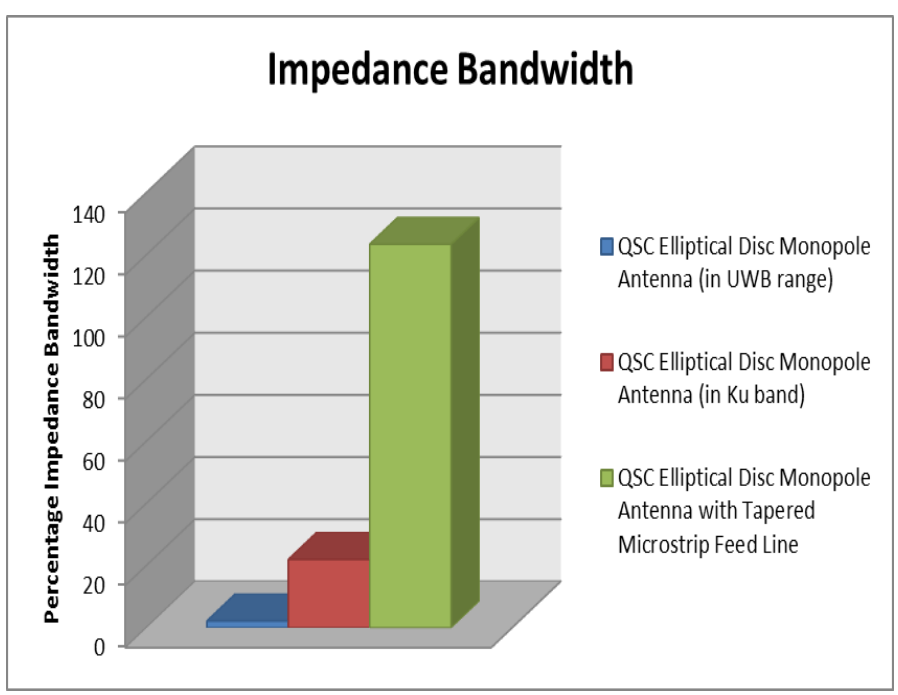

Chart -1: Bar chart comparing the impedance bandwidth of the QSC elliptical disc monopole antenna in the UWB range, $\mathrm{Ku}$ band and with that of the QSC elliptical disc monopole antenna with tapered microstrip feed line

The extent to which the tapered microstrip feed line proposal has boosted the impedance bandwidth of the antenna is discussed in Chart -1. The comparison is done between the conventional elliptical disc monopole antenna, the compact QSC elliptical disc monopole antenna with a microstrip feed line and the antenna proposed here which is fed with the tapered microstrip feed line. It is seen that the antenna proposed here exhibits a considerable large percentage impedance bandwidth of $123.46 \%$ when compared to the compact antenna without the tapered feed line whose impedance bandwidth in the UWB range was narrowed due to 
the inclusion of the notch in the ground plane. The antenna proposed here thus, exhibits an ultra-wide impedance bandwidth extending from the UWB range to the Ku band of the spectrum

\section{CONCLUSIONS}

A compact quasi self-complementary elliptical disc monopole antenna with tapered microstrip feed line was designed and simulated here. The adoption of the quasi self-complementary structure has led to $62 \%$ size reduction. The miniaturization attained and the return loss performance of the proposed antenna is compared with that of the conventional elliptical disc monopole antenna and the compact quasi selfcomplementary elliptical disc monopole antenna fed with a microstrip feed line.

The quasi self-complementary structure espoused to miniaturize the antenna has narrowed the impedance bandwidth of the antenna in the UWB range although it led to an additional operating band in the $\mathrm{Ku}$ region. This drawback was overcome by feeding the antenna with a tapered microstrip feed line. The resulting antenna has thus been able to achieve both miniaturization and acceptable performance over the UWB range and beyond

\section{REFERENCES}

[1]. Jasmine Mannil Abraham, Dr. Josemin Bala, "Compact Quasi Self-Complementary Elliptical Disc Monopole Antenna" ELECTRON5,Proceedings of the Fifth National Conference on Recent Trends in Communication, Computing and Signal Processing, vol.5,pp. 14-18, February 2014

[2]. Ashraf A. Adam, Sharul Kamal Abdul Rahim, Kim Geok Tan and Ahmed Wasif Reza, "Design of 3.1-12 GHz Printed Elliptical Disc Monopole Antenna with Half Circular Modified Ground Plane for UWB Application", Springer Science and Transaction Media, vol. 69, pp.535-549, April 2012

[3]. Dr. Mohammed Matin, "Ultra Wide band Printed Antenna Design"Ultra Wide Band Communication: Novel TrendsAntennas and Propagation, 2011,vol. 1,pp. 1-207

[4]. Kalteh, A.-A., Fallahi, R., \& Roozbahani, M. G.,” Design of a band-notched microstrip circular slot antenna for UWB communication." Progress in Electromagnetics Research C,2010, vol. 12, pp. 113-123

[5]. Behjati, Z., \& Azarmanesh, M. N., " Dual band-notched semi-elliptical monopole antenna with two branch feed line.", Progress in Electromagnetics Research Letters,2009, vol.12, pp.69-78.

[6]. Akhoondzadeh-Asl, L., Fardis, M., Abolghasemi, A., \& Dadashzadeh, G., "Frequency and time domain characteristic of a novel notched frequency UWB antenna.", Progress in Electromagnetics Research,2008, vol. 80, pp. 237-348

[7]. Z.Chen, T.See and X.Qing, "Small Printed Ultra wideband Antenna with Reduced Ground Plane Effect", IEEE
Transactions on Antennas and Propagation, vol. 55, no. 2, pp. 383-388, February 2007

[8]. Zhou, H. J., Liu, Q. Z., Li, J. F.,\&Guo, J. L., “A swallowtailed wideband planar monopole antenna with semi-elliptical base", Journal of Electromagnetic Waves and Applications,2007, vol.21, no.9, pp.1257-1264.

[9]. Ray, K. P., \& Rang, Y. ,'Ultra-wideband printed elliptical monopole antennas", IEEE Transactions on Antennas and Propagation,2007, vol. 55, no.4, pp. 1189-1192.

[10]. Ren, W., Deng, J. Y., \& Chen, K. S., " Compact PCB monopole antenna for UWB applications.", Journal of Electromagnetic Waves and Applications, 2007, vol.21, no.10, pp.1411-1420.

[11]. A.M.Abbosh, M.E.Bialkowski, M.V.Jacob and J.Mazierska, "Design of a compact ultra-wideband antenna", Microwave and Optical Technology Letter, vol. 48, pp. 15151518, August 2006.

[12]. K. Bahadori and Y. Rahmat-Samii, "An Elliptic-Card UWB Antenna for Wireless Communications", The first European Conference on Antennas and Propagation (EuCAP 2006), Nice, France, 6-10 November, 2006

[13]. T.Yang, W.A.Davis and W.L.Stutzman, "Small Planar Ultra-wideband antenna with top-loading", IEEE Antennas and Propagation Society International Symposium 2005, pp. 479-482, July 2005.

[14]. MUSHIAKE, Y, “A report on Japanese development of antennas: from the Yagi-Uda antenna to self-complementary antennas”, IEEE Antennas Propag. Mag., 2004, vol. 46, no. 4, pp. 47-60.

[15]. WONG, K., WU, T., SU, S., LAI, J., "Broadband printed quasi-self-complementary antenna for 5.2/5.8 GHz WLAN operation", Microw. Opt. Technol. Lett., 2003, vol. 39, no. 6, pp. 495-496

[16]. MUSHIAKE, Y, "Self-complementary antennas", IEEE Antennas Propag. Mag., 1992, vol. 34, no. 6, pp. 23-29.

[17]. KRAUS, J. Antennas for All Applications. McGrawHill, Inc., 2002. 